\title{
Clinical Profile of Neonates with Perinatal Asphyxia in a Tertiary Care Hospital of Central Nepal
}

\author{
Sweta Kumari Gupta, ${ }^{1}$ Bhabani Kanta Sarmah, ${ }^{1}$ Damodar Tiwari, ${ }^{1}$ Amshu Shakya, ${ }^{1}$ Dipendra Khatiwada ${ }^{2}$ \\ ${ }^{1}$ Department of Pediatrics, ${ }^{2}$ Department of Community Medicine, College of Medical Sciences, Bharatpur, Chitwan, Nepal.
}

\section{ABSTRACT}

Introduction: Birth asphyxia is a serious clinical problem worldwide. It claims approximately 9 million deaths each year. It can lead to serious neurological sequaele, such as cerebral palsy, mental retardation, and epilepsy.

Methods: All babies admitted in College of Medical Sciences Teaching Hospital, Chiwan, Nepal, NICU from January 2013 to December 2013 with a diagnosis of birth asphyxia (5 min Apgar $<7$ or those with no spontaneous respirations after birth) were included in the study $(n=125)$. This was a descriptive observational study. Clinical information was collected (gravida, hour at presentation, mode of delivery, sex of baby, gestational age of the baby, requirement of resuscitation). Neonates were admitted to NICU, observed for complications and managed as per hospital protocol.

Results: Among the 722 neonates admitted to NICU, 125 had perinatal asphyxia (17.3\%). Babies with Hypoxic ischemic encephalopathy(HIE) Grade I had a very good outcome but HIE III was associated with a poor outcome. Outborn neonates had higher grades of perinatal asphyxia as compared to inborns $(p=0.018)$. Term gestation, Males and Multigravida were associated with a higher rate of birth asphyxia. $22.4 \%$ neonates were delivered via caesarean section and $74.4 \%$ required bag and mask ventilation at birth.

Conclusions: Birth asphyxia was one of the commonest causes of admission NICU. Babies with HIE Grade III had a very poor prognosis. Outborn neonates with birth asphyxia had a higher mortality. Males were frequently affected than females.

Keywords: birth asphyxia; HIE; mortality; measurement.

\section{INTRODUCTION}

A breath of air is vital from the start of life out of mother's womb. Deprivation of oxygen after birth leads to impairment of various organs of our body. For community use, Birth asphyxia is defined as the failure to initiate and sustain breathing at birth. Globally, it accounts for an estimated 900,000 deaths each year and is one of the primary causes of early neonatal mortality. ${ }^{1}$ Guidelines for neonatal resuscitation, such as those endorsed by WHO and the American Academy of Pediatrics, represent a standard practice set that improves outcomes in asphyxiated newborns. These algorithms stress the importance of drying, stimulating and warming babies in distress, as well as clearing their airways. In the face of persistent apnoea or bradycardia, ventilation with the use of bag-and-mask or equivalent device is indicated, and is felt by many to constitute the critical step in managing asphyxiated infants. ${ }^{2}$

Diagnosis of asphyxia is usually made on the clinical

Correspondence: Dr. Sweta Kumari Gupta, Department of Pediatrics, College of Medical Sciences, Bharatpur, Chitwan, Nepal. E-mail: doctorsweta84@gmail.com, Phone-+977-9807265498. 
criteria. The most frequent abnormalities involved are found in kidneys $(50 \%)$ followed by CNS $(28 \%)$, cardiovascular (25\%) and pulmonary system (23\%). The spectrum of disorders to which neonate is exposed as a result of asphyxia includes hypoxic ischemic encephalopathy (HIE), acute renal failure, necrotizing enterocolitis, systemic hypotension, cardiogenic shock, congestive cardiac failure, DIC, meconium aspiration and wide variety of metabolic problems including hyponatremia, hypoglycemia, hypocalemia and metabolic acidosis. ${ }^{3}$

In most cases, infants successfully recover from hypoxia episodes; however, some patients may develop $\mathrm{HIE}$, leading to permanent neurological conditions or impairment of different organs and systems. ${ }^{4}$ According to World Health Organization estimates in the developing countries, $3 \%$ of all infants (3.6 million) suffer from moderate to severe birth asphyxia of which $23 \%(840,000)$ die and approximately the same number develop serious sequel. ${ }^{5}$

In this background, we decided to do a study in a center outside Kathmandu valley where very few literatures are available.

The objectives of the study were to assess the clinical profile of neonates with perinatal asphyxia and severity of birth asphyxia with HIE in terms of mortality.

\section{METHODS}

Descriptive observational study was carried out on neonates with the diagnosis of birth asphyxia at College of Medical Sciences Teaching Hospital, Bharatpur, Chitwan, Nepal. This is a tertiary level hospital with a well-equipped and established Paediatric department including Neonatal Intensive Care Unit (Level-III) and Paediatric Intensive Care Unit facility.

A total of 125 consecutive asphyxiated newborn from January 2013 to December 2013 who met the inclusion criteria were enrolled in the study. All newborn babies with a clinical diagnosis of birth asphyxia (newborn with history of delayed cry or APGAR score of less than seven in five minutes) were included in the study.

Hour at presentation, gender, gestational age, Apgar score, resuscitation required, complications during hospital stay, duration of hospital stay, the outcome of birth asphyxia with respect to mortality in different stages of HIE as proposed by Sarnat ${ }^{6}$ were also determined. Ethical clearance was taken from the institutional review committee before the initiation of the study.

Data was entered and analyzed using SPSS 20. Statistical method included determination of $p$-value using Chi - square test. For tables where expected frequencies were less than five, Fisher's Exact test was performed. Statistical test was considered significant at 0.05 level of confidence.

\section{RESULTS}

Between January 2013 and December 2013, there were 722 admissions to NICU. Among which 125 cases were of birth asphyxia and accounted for 17.3 $\%$ of NICU admissions. There were more males than females $90(72.0 \%)$ and $35(28.0 \%)$ respectively. The majority were of term gestation ( $n=94,75.2 \%$ ) and $31(24.8 \%)$ were preterm. Most of the admissions ( $n=116,92.8 \%$ ) occurred within the first 6 hours of life. The remaining nine neonates $(7.2 \%)$ were admitted after 6 or more than six hours of life. Among admitted neonates, 55 (44.0\%) were inborn and 77 (56.0\%) were outborn. Neonates born to primigravida mothers accounted for $37.6 \%$ of cases and those born to multigravida mothers were $62.4 \%(n=78)$.

The majority of neonates were born via spontaneous vaginal delivery $(n=81,64.8 \%)$. Twenty eight $(22.4$ $\%)$ were born via caesarean section, and instrumental deliveries consisted of $12.8 \%(n=16)$. Among total cases, $93(74.4 \%)$ required bag and mask ventilation during resuscitation while $20(16.0 \%)$ required only tactile stimulation while $12(9.6 \%)$ required intubation and IPPV.

There were $77(61.6 \%)$ cases of Perinatal asphyxia without HIE, $13(10.4 \%)$ cases with HIE Grade I, 30 (24.0\%) cases with HIE Grade II, and 5 (4.0\%) cases with HIE Grade III. Among these cases, 4 (57.1\%) among HIE Grade III, 3 (42.9\%) among HIE Grade II died while none in HIE Grade I and without HIE expired. This difference was statistically significant (Table $3, p<0.001)$. And the neonates who had perinatal asphyxia of higher grades were mostly outborn babies (Table 2, p-value $=0.018$ ). Among neonates who died, $4(57.1 \%)$ presented within six hours of life and 3 $(42.9 \%)$ presented after six or more than six hours of life. 
Gupta et al. Clinical Profile of Neonates with Perinatal Asphyxia in a Tertiary Care Hospital of Central Nepal

\begin{tabular}{|c|c|c|c|c|}
\hline Category & Subcat-egories & Number & $\%$ & p-value \\
\hline \multirow{2}{*}{ Gravida } & Primi & 47 & 37.6 & \multirow{2}{*}{0.006} \\
\hline & Multi & 78 & 62.4 & \\
\hline \multirow{2}{*}{$\begin{array}{l}\text { Hour of } \\
\text { presentation }\end{array}$} & $<6$ hours & 116 & 92.8 & \multirow{2}{*}{$<0.001$} \\
\hline & $\geq 6$ hours & 9 & 7.2 & \\
\hline \multirow{2}{*}{$\begin{array}{l}\text { Gestational } \\
\text { age }\end{array}$} & Term & 94 & 75.2 & \multirow{2}{*}{$<0.001$} \\
\hline & Preterm & 31 & 24.8 & \\
\hline \multirow{2}{*}{ Sex } & Male & 90 & 72.0 & \multirow{2}{*}{$<0.001$} \\
\hline & Female & 35 & 28.0 & \\
\hline \multirow{2}{*}{ Place of birth } & Inborn & 55 & 44.0 & \multirow{2}{*}{0.180} \\
\hline & Outborn & 70 & 56.0 & \\
\hline \multirow{3}{*}{$\begin{array}{l}\text { Mode of } \\
\text { delivery }\end{array}$} & $\begin{array}{l}\text { Normal } \\
\text { vaginal }\end{array}$ & 81 & 64.8 & \multirow{3}{*}{$<0.001$} \\
\hline & Caesarean & 28 & 22.4 & \\
\hline & Instrumental & 16 & 12.8 & \\
\hline \multirow{3}{*}{$\begin{array}{l}\text { Resuscitation } \\
\text { required }\end{array}$} & $\begin{array}{l}\text { Tactile } \\
\text { Stimulation }\end{array}$ & 20 & 16.0 & \multirow{3}{*}{$<0.001$} \\
\hline & $\begin{array}{l}\text { Bag and } \\
\text { Mask }\end{array}$ & 93 & 74.4 & \\
\hline & $\begin{array}{l}\text { Intubation } \\
\text { and IPPV }\end{array}$ & 12 & 9.6 & \\
\hline \multirow[t]{4}{*}{$\begin{array}{l}\text { Perinatal } \\
\text { asphyxia }\end{array}$} & with out HIE & 77 & 61.6 & \multirow{4}{*}{$<0.001$} \\
\hline & with HIE I & 13 & 10.4 & \\
\hline & with HIE II & 30 & 24.0 & \\
\hline & with HIE III & 5 & 4.0 & \\
\hline
\end{tabular}

Table 2. Distribution of Perinatal asphyxia according to place of delivery.

\begin{tabular}{|llll|}
\hline Category & $\begin{array}{l}\text { Inborn } \\
\mathrm{n}(\%)\end{array}$ & $\begin{array}{l}\text { Outborn } \\
\mathrm{n}(\%)\end{array}$ & p-value \\
PA with out HIE & $40(51.9)$ & $37(48.1)$ & \\
PA with HIE I & $7(53.8)$ & $6(46.2)$ & 0.018 \\
PA with HIE II & $8(26.7)$ & $22(73.3)$ & \\
PA with HIE III & $0(0)$ & $5(100)$ & \\
\hline
\end{tabular}

Table 3. Severity of perinatal asphyxia as per mortality in cases with perinatal asphyxia.

\begin{tabular}{|llll|}
\hline Category & $\begin{array}{l}\text { Number of } \\
\text { deaths }\end{array}$ & $\begin{array}{l}\text { Percentage } \\
\text { of deaths }\end{array}$ & p-value \\
PA with out HIE & 0 & 0 & \\
PA with HIE I & 0 & 0 & \\
PA with HIE II & 3 & 42.9 & $<0.001$ \\
PA with HIE III & 4 & 57.1 & \\
\hline
\end{tabular}

\begin{tabular}{|llll|}
\hline \multicolumn{4}{|l|}{ Table 4. Mortality in neonates with perinatal asphyxia } \\
with relation to hour at presentation.
\end{tabular}

\section{DISCUSSION}

Inspite of major advances in monitoring technology and knowledge of fetal and neonatal pathologies, perinatal asphyxia or more appropriately, HIE remains a serious condition causing significant mortality and long term morbidity. It is one of the commonest causes of hospital admission of a newborn. ${ }^{7}$ A hospital based study in Nepal estimated that birth asphyxia accounted for $24 \%$ of perinatal mortality rate. ${ }^{8}$ One of the present challenges is the lack of a gold standard for accurately defining birth asphyxia. Because of same reason the incidence of birth asphyxia is difficult to quantify. The frequency of birth asphyxia was $17.3 \%$ in our study, while it varies from $9.3 \%$ to $25 \%$ in different studies. ${ }^{9-12}$ This variation may be due to different operational definition of birth asphyxia adopted by different researchers, APGAR score at $1 \mathrm{~min}$ and $5 \mathrm{~min}$, duration of resuscitation, breathing effort at 1 min etc. Many babies $(64.2 \%)$ in this study were born to multigravida mothers. It is in agreement with study by Azam Min Multan which showed the incidence of birth asphyxia with multigravida to be $53 \%$, with incidence of birth asphyxia in neonate born to grand multipara being $34 \%{ }^{13}$. Other studies have found perinatal asphyxia more commonly in newborn babies of primigravida mothers. ${ }^{10,14}$ Most of our admissions (92.8\%) occurred during the first 6 hours of life. Another study conducted in Hyderabad found $61.6 \%$ of admissions during the first 6 hours. ${ }^{12}$ This may be due to presence of a Government Hospital in the nearby vicinity of our hospital. It also emphasizes the fact that most of the neonatal problems present within the first day of life, during which early detection and intervention is crucial.

The majorities (75.2\%) were term gestation and $24.8 \%$ were preterm. This finding was different from other centres where the percentages of premature babies were lower $(9.2 \%$ to $20 \%) .{ }^{10,14}$ This is probably due to the fact that our centre is fully functional level three NICU, and that antenatal cases in labour with gestational ages below 34 weeks were referred to our centre. Male to female ratio in our study was 2.6:1, males constituted $72.0 \%$ of all babies in our study. It is comparable with most other studies where male dominance was recorded, $55.88 \%$ in study by Dongol 
et al, $^{10} 55.5 \%$ in study by Kumar et al, ${ }^{15} 61 \%$ by Shrestha et al. ${ }^{16} \mathrm{~A}$ higher percentage of babies were delivered through caesarean section $(22.4 \%), 12.8 \%$ were instrumental delivery and rest were vagjnal deliveries. The rate of caesaeren delivery in our study corresponds to that given by Kumar et al ${ }^{17}$ (25\%) and Yelamali (25.76). ${ }^{14}$ Macdonald et al, found that there was an increase in the incidence of asphyxia in caesarean birth but when this was broken down into risk category based on primary indication for caesarean section only the high risk category was associated with birth asphyxia which indicates that the procedure itself was not causative in producing asphyxia. ${ }^{18}$ In our study $74.4 \%$ cases required bag and mask ventilation, $16 \%$ required only stimulation and only $9.6 \%$ required intubation with IPPV. This emphasizes that the basic grass root level staffs need to be taught the skill of bag and mask ventilation to prevent severe birth asphyxia.

Only $4 \%$ cases had Grade III perinatal asphyxia, 24\% had Grade II, $10.4 \%$ had Grade I and $61.6 \%$ had no perinatal asphyxia. As given in Table 2, higher Grades of perinatal asphyxia were found in outborn babies. This reiterates that fact that grass root level staffs need more training in adept management of delivery to prevent birth asphyxia. The mortality was highest in HIE Grade III (57.1\%) followed by Grade II (42.9\%), no deaths were observed in neonates with Grade I and those without HIE (Table 3). Similar trend was seen in many other studies. 10,15,19 Mortality also was significantly associated with hour at presentation, out of 7 mortalities, $57.1 \%$ neonates who presented within 6 hours died as compared to $42.9 \%$ who presented after 6 hours (Table 4). Study conducted in Liaquat University of Medical \& Health Sciences, Jamshoro, Hyderabad reported higher mortality in neonates presenting after 6 hours of birth. ${ }^{7}$ This may be due to other morbidities associated along with perinatal asphyxia.

\section{CONCLUSIONS}

Birth asphyxia is one of the commonest cause of admission of a newborn to NICU and a leading cause of morbidity and mortality in neonates. Deliveries at peripheries and home, i.e., outborn babies had poor outcome and early admission to NICU and early intervention had better outcome. Babies with HIE Grade II and III had poor outcome.

So, early referral of mother with complicated labour to the hospital can minimize the birth asphyxia and its complications. It may be possible to reduce the occurrence of asphyxia and its complications by improving antenatal, intrapartum and neonatal care services in the community. In our context, training programs aimed for ANWs and midwives in neonatal resuscitation especially bag and mask ventilation can lower the burden of asphyxiated babies to a high extent.

\section{LIMITATIONS}

It is a hospital based study which cannot be generalized to the entire population and that this study is urban based and the results may not be comparable to rural population.

\section{REFERENCES}

1. Lawn JE, Manandhar A, Haws RA, Darmstadt GL. Reducing one million child deaths from birth asphyxia: a survey of health systems gaps and priorities. Health Res Policy Syst 2007;5: 4. doi: 10.1186/1478-4505-5-4. PMID: 17506872.

2. Rehan VK, Phibbs RH. Delivery room management. In: Avery's neonataology: pathophysiology and management of the newborn. 6th ed. Philadelphia: Lippincott Williams \& Wilkins Press; 2005.

3. Mohan K, Mishra PC, Singh DK. Clinical profile of birth asphyxia in newborn. International Journal of Science \& Technology. 2013;3(1):10-9.

4. Fattuoni C, Palmas F, Noto A, Fanos V, Barberini L.Perinatal Asphyxia: A Review from a Metabolomics Perspective. Molecules 2015, 20, 7000-7016; doi:10.3390/ molecules20047000.
5. State of the World Children. UNICEF, 2009. Maternal and newborn health. http://www.unicef.org/scowc09/report/ report.php. [Last accessed on $2014 \mathrm{Feb} 20$ ].

6. Sarnat HB, Sarnat MS. Neonatal encephalopathy following fetal distress. A clinical and electroencephalographic study. Arch Neurol 1976; 33: 696-705.

7. Memon IA. Neonatal resuscitation. J Coll Physiol Surg Pak 1995; 5(4):163-4

8. Ellis M, Manandhar DS, Manandhar N, Wyatt J,Balam AJ, Costello AM. Stillbirths and neonatal encephalopathy in kathmandu, Nepal: An estimate of the contribution of birth asphyxia to perinatal mortality in low income urban population. Paediatr Perinat Epidermiol 2000;14:39-52.

9. Shakya A, Shrestha D, Shakya H, Shah SC, Dhakal AK. Clinical profile and outcome of neonates admitted to the Neonatal Care Unit at a teaching hospital in Lalitpur, Nepal. Journal of Kathmandu Medical College 2014;3(10):144-8. 
10. Dongol S, Singh J, Shrestha S, Shakya A. Clinical Profile of Birth Asphyxia in Dhulikhel Hospital: A Retrospective Study. J. Nepal Paediatr. Soc 2010;30(3):141-6.

11. Begum T, Islam MR. Clinical profi le and outcome of 100 neonates in perspectives of neonatal care in a tertiary hospital. J Shaheed Suhrawardy Med Coll. 2012;2(1):2-3.

12. Memon S, ShaikhS, BibiS. To compare the outcome (early) of neonates with birth asphyxia in-relation to place of delivery and age at time of admission. JPMA 2012;62(12):1277-81.

13. Azam M, Malik F, Khan P. Birth asphyxia risk factors. The professional 2004;11(4):416-423.

14. Yelamali BC, Panigatti P, Pol R, Talawar KB, Naik S, Badakali A. Outcome of newborn with birth asphyxia in tertiary care hospital - a retrospective study. Medica Innovatica 2014;3(2):59-64.

15. Kumar A, Suruchi S,Kumar V, Pathak A, Banerjee DP. Clinical Profile and Short-term Outcome of Hypoxic Ischemic Encephalopathy among Birth Asphyxiated Babies in Katihar Medical College Hospital. Journal of Clinical Neonatology 2014;3(4):195-9.
16. Shrestha M, Shrestha L, Shrestha PS. Profile of asphyxiated babies at Tribhuvan university teaching hospital. J Nepal Paediatr Soc 2009; 29:3-5

17. Kumar S, Akbar Nijamani M, Menon S. Risk factors in Birth Asphyxia at Liaquat University Hospital, Hyderabad. MC 2014;20(1):35-8.

18. Macdonald HM, Mullingan JC. Neonatal asphyxia-relation of obstetric and neonatal complication to neonatal mortality in 38, 405 deliveries J Pediatr 198096 : 898-907.

19. Babu BVA, Devi SS, Kumar BK. "Birth asphyxia - Incidence and immediate outcome in relation to risk factors and complications". Int J Res Health Sci [Internet]. 2014 Oct 31;2(4):1064-71. Available from http://www.ijrhs.com/ issues.phpval=Volume2\&iss=Issue4. 